Article

\title{
Morin-5'-Sulfonic Acid Sodium Salt (NaMSA) Attenuates Cyclophosphamide-Induced Histological Changes in Genitourinary Tract in Rats-Short Report
}

\author{
Anna Merwid-Ląd 1,*(D), Dorota Ksiądzyna ${ }^{1}$, Agnieszka Hałoń ${ }^{2}$, Danuta Szkudlarek ${ }^{3}$, Małgorzata Trocha ${ }^{1}$, \\ Marta Szandruk-Bender ${ }^{1}$ (D), Agnieszka Matuszewska ${ }^{1}$ (D) Beata Nowak ${ }^{1}$ (D), Tomasz Sozański ${ }^{1}$, Anna Kuźniar ${ }^{4}$ (D) \\ and Adam Szeląg ${ }^{1}$ (D)
}

check for updates

Citation: Merwid-Ląd, A.;

Ksiądzyna, D.; Hałon, A.; Szkudlarek

D.; Trocha, M.; Szandruk-Bender, M.;

Matuszewska, A.; Nowak, B.;

Sozański, T.; Kuźniar, A.; et al.

Morin-5'-Sulfonic Acid Sodium Salt

(NaMSA) Attenuates

Cyclophosphamide-Induced

Histological Changes in

Genitourinary Tract in Rats-Short

Report. Pharmaceuticals 2021, 14, 192.

https://doi.org/10.3390/ph14030192

Academic Editor: Mary Meegan

Received: 1 February 2021

Accepted: 23 February 2021

Published: 26 February 2021

Publisher's Note: MDPI stays neutral with regard to jurisdictional claims in published maps and institutional affiliations.

Copyright: (c) 2021 by the authors. Licensee MDPI, Basel, Switzerland. This article is an open access article distributed under the terms and conditions of the Creative Commons Attribution (CC BY) license (https:/ / creativecommons.org/licenses/by/ $4.0 /)$.
1 Department of Pharmacology, Wroclaw Medical University, ul. Mikulicza-Radeckiego 2, 50-345 Wrocław, Poland; dorota.ksiadzyna@umed.wroc.pl (D.K.); malgorzata.trocha@umed.wroc.pl (M.T.); marta.szandruk@umed.wroc.pl (M.S.-B.); agnieszka.matuszewska@umed.wroc.pl (A.M.);

beata.nowak@umed.wroc.pl (B.N.); tomasz.sozanski@umed.wroc.pl (T.S.); adam.szelag@umed.wroc.pl (A.S.)

2 Department of Pathomorphology and Oncological Cytology, Wroclaw Medical University, ul. Borowska 213, 50-556 Wrocław, Poland; agnieszka.halon@umed.wroc.pl

3 Department of Pathomorphology, Wroclaw Medical University, ul. Marcinkowkiego 1, 50-368 Wrocław, Poland; danuta.szkudlarek@umed.wroc.pl

4 Department of Inorganic and Analytical Chemistry, Rzeszow University of Technology, al. Powstańców Warszawy 6, 35-959 Rzeszów, Poland; akuzniar@prz.edu.pl

* Correspondence: anna.merwid-lad@umed.wroc.pl; Tel.: +48-71-784-1442

Abstract: Cyclophosphamide (CPX) exerts toxicity in the urogenital system. The current study was designed to evaluate the effect of morin-5'-sulfonic acid sodium salt (NaMSA) on CPX-induced urogenital toxicity in rats. NaMSA (100 mg/ $\mathrm{kg} /$ daily) and CPX (15 mg/kg/daily) alone or in combination and $0.9 \% \mathrm{NaCl}$ (as a control) were given intragastrically for 10 days. Testes and epididymes from male and urinary bladders from male and female rats were evaluated histologically. In testes and epididymes, morphological changes and relative decrease in sperm count were assessed. In urinary bladders edema, hemorrhage and urothelium erosions were described by 0-2 points scoring system. Reproductive score (RS - in total 6 points) and urinary bladder score (BS-in total 6 points) were thereafter calculated. In CPX-receiving group RS (2.7) and BS (3.3) were significantly higher than in the control ( 0.5 and 0.25 for RS and BS, respectively). Co-administration of NaMSA reversed most of the morphological changes, which was reflected by lower RS and BS score $(0.5$ and 1.2 for RS and BS, respectively). The preliminary findings suggest that NaMSA may attenuate $\mathrm{CPX}$-induced histological changes in rat urogenital tract.

Keywords: NaMSA; cyclophosphamide; histopathology; testis; urinary bladder

\section{Introduction}

The male reproductive system is very sensitive to noxious factors and permanent or transient infertility is a great clinical problem, especially in younger patients. There are still not too many possibilities to counteract these drug-induced complications. Among many reasons of decreased fertility or even infertility such as anatomical pathologies, diabetes, obesity, smoking, cancers, radiation or environmental toxins, adverse effects of many anticancer agents are very important [1-3].

Cyclophosphamide (CPX) is a conventional anticancer drug belonging to the alkylating agents [4]. Despite introduction in clinical practice, many targeted treatment options as immunosuppressant or anticancer drugs [5], it is estimated that still every year many patients develop and are diagnosed with cancers, which are the indication for CPX administration [6]. 
Cyclophosphamide exerts significant adverse effects in the urinary tract and affects the male reproductive system, causing disorders of spermatogenesis with oligo- and azoospermia, testicular atrophy in men taking this drug and sometimes infertility, which may be irreversible. Lesions caused by CPX in the urinary tract are also well described and are observed after both short- or long-term treatment. In human hemorrhagic cystitis, pyelonephritis and hematuria are common complications [7]. With the mechanism of the urinary tract, especially the urinary bladder, injury is multifactorial and involves first of all the reaction of CPX metabolite (acrolein) with urothelium with subsequent inflammatory cascade. In the prevention of urinary toxicity, mainly life-threatening hemorrhagic cystitis, there are a few possibilities with good hydration, systemic administration of mesna (whose efficacy in this indication is recently discussed and doubtful), local irrigation of the urinary bladder with various substances or sometimes even surgical, invasive procedures $[4,6]$. Much less is known about the prevention of chronic injury of kidneys or the reproductive system. Therefore, there is still a great need to search for compounds that may decrease CPX-induced tissue toxicity instead or as adjuvant to standard prevention schedules and in this way, decrease mortality due to complications of anticancer therapy and increase patients' quality of life. Plant-derived substances and their chemically modified derivatives are in the interest of scientists in a variety of medical indications. Many different compounds have been until now tested in experimental studies for reduction of cyclophosphamide-induced urogenital toxicity, especially in male rats using models of acute or chronic cyclophosphamide administration [8-10].

Morin-5'-sulfonic acid sodium salt (NaMSA) is a derivative of natural flavonoid morin, but as a sodium salt exerts much better water-solubility. We have described in our previous papers that NaMSA reversed some CPX-induced changes in oxidative stress parameters in liver and kidney in rat models of 10 days CPX administration at a daily dose of $15 \mathrm{mg} / \mathrm{kg}$ [11] and attenuated pathological changes in intestine morphology [12]. Generation of oxidative radicals may be one of the factors responsible for damages observed in male gonads and in the urinary tract $[10,13-15]$. In this paper, we describe preliminary results of the influence of NaMSA administration on CPX-induced toxicity in male rat gonads based on the histopathological evaluation of testes and epididymes and the effect of NaMSA on histological toxicity in the urinary bladders of both sexes.

\section{Results}

\subsection{Tested and Epididymes Evaluation}

Results of the testes, epididymes and sperm score, and urinary bladder score are presented in Figures 1 and 2. Intragastric CPX administration for 10 days in a daily dose of $15 \mathrm{mg} / \mathrm{kg}$ caused significant increase in testes and epididymes histological lesions described as irregular and diminished seminiferous tubules of a mild or severe grade along with various levels of decreased sperm count within the lumen of seminiferous tubules. Co-treatment with NaMSA in a daily dose of $100 \mathrm{mg} / \mathrm{kg}$ reversed those change, which was reflected by decreased testes and epididymes score. Representative histological changes for tested groups in testes and epididymes are presented in Figures 3 and 4, respectively. 


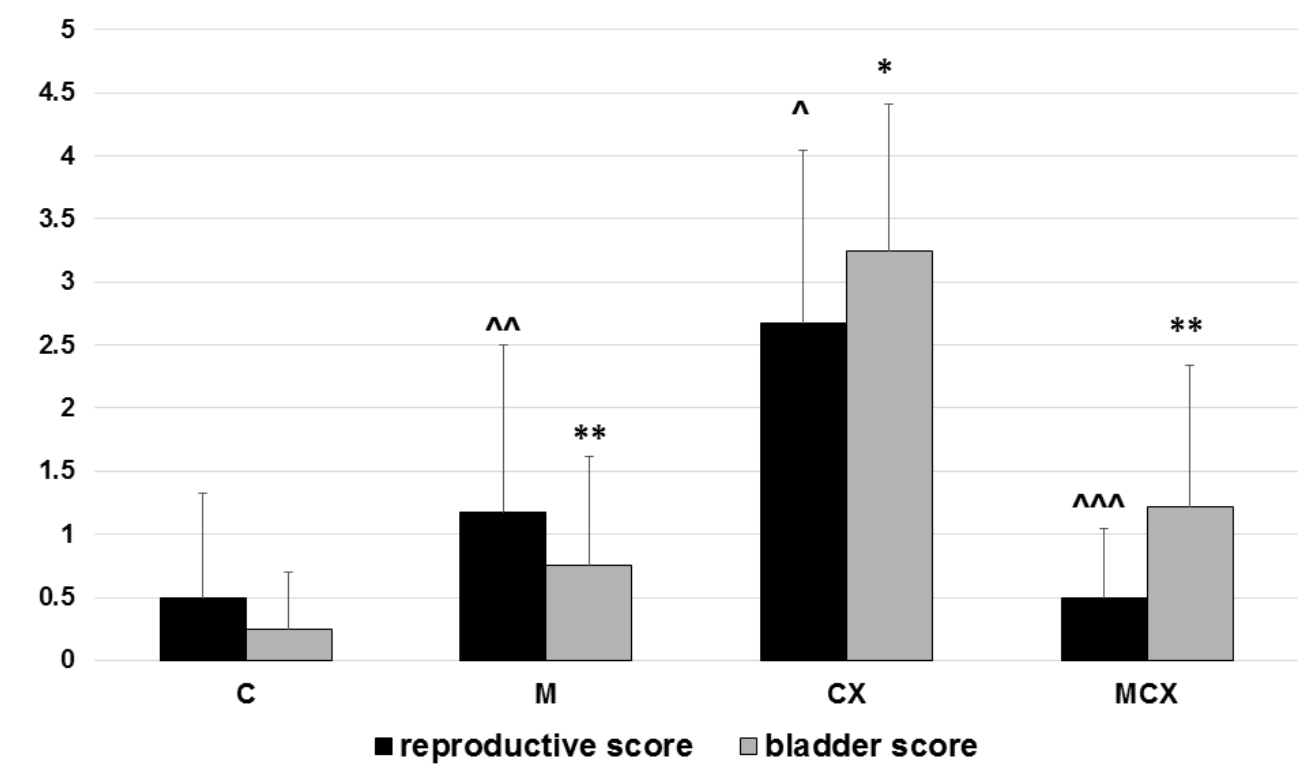

Figure 1. Total reproductive score (testes, epididymes and sperm, 0-6 points) and total urinary bladder score (hemorrhage, edema, erosions, 0-6 points). Scoring system described in the Material and Methods section. Bladder score: ${ }^{*} p<0.001$, CX vs. C; ${ }^{* *} p<0.001, \mathrm{M}$ vs.CX and MCX vs. CX. Reproductive score: ${ }^{\wedge} p<0.01, \mathrm{CX}$ vs. ; $^{\wedge}{ }^{\wedge} p<0.05, \mathrm{M}$ vs. CX and ${ }^{\wedge} p<0.01, \mathrm{MCX}$ vs. CX. Data presented as mean values and SD.

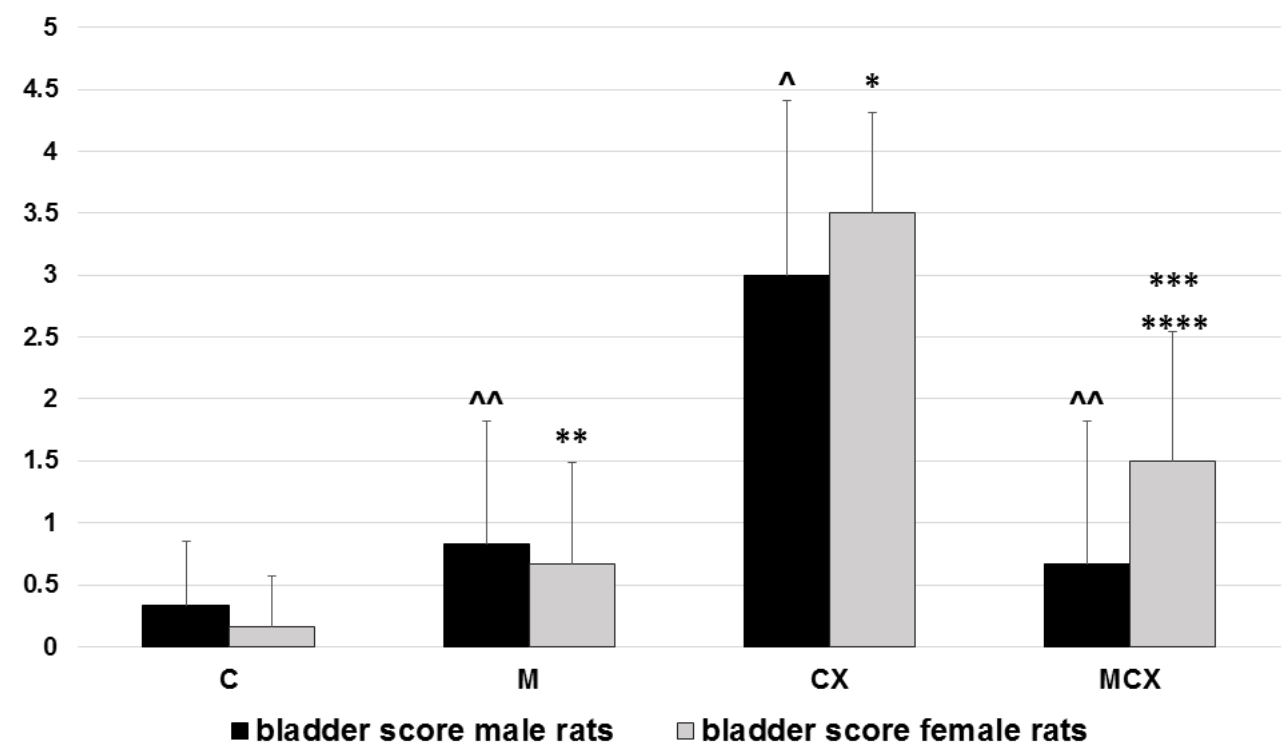

Figure 2. Total urinary bladder score (hemorrhage, edema, erosions, 0-6 points) in male and female rats. Scoring system described in the Material and Methods section. Male rats: ${ }^{\wedge} p<0.001, \mathrm{CX}$ vs. $\mathrm{C} ;{ }^{\wedge} p<0.01, \mathrm{M}$ vs. $\mathrm{CX}$ and $\mathrm{MCX}$ vs. CX. female rats: ${ }^{*} p<0.001, \mathrm{CX}$ vs. C; ${ }^{* *} p<0.001, \mathrm{M}$ vs.CX; ${ }^{* * *} p<0.01, \mathrm{MCX}$ vs. CX; ${ }^{* * * *} p<0.05, \mathrm{MCX}$ vs. C. Data presented as mean values. 


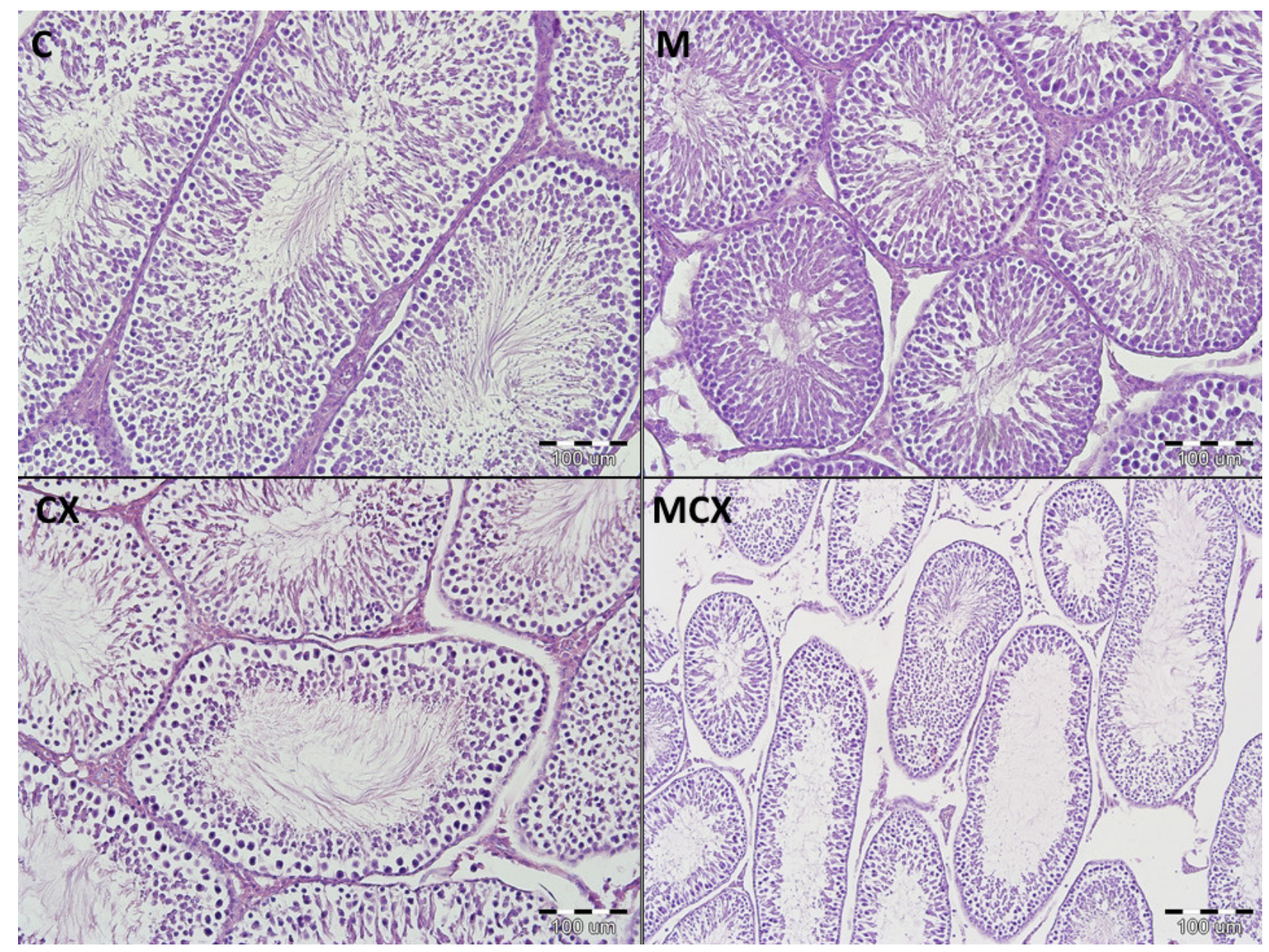

Figure 3. Histological cross-sections of testes (HE staining, magnification $200 \times$ ). C — control group-appearance of normal testis with orderly maturation of germ cells from the base to the center of the lumen: numerous spermatogonia (along the basement membrane), primary and secondary spermatocytes, spermatids, and spermatozoa; M- Morin- $5^{\prime}$-sulfonic acid sodium salt (NaMSA) receiving group—appearance of normal testis: the seminiferous tubules with numerous germ cells; $\mathrm{CX}$-cyclophosphamide receiving group — changes grade 2 - the seminiferous tubules with loss of germ cells, there is an orderly maturation of germ cells from the base to the center of the lumen, but the number of spermatogonia (along the basement membrane), primary and secondary spermatocytes, spermatids, and spermatozoa is decreased; MCX-group receiving cyclophosphamide and NaMSA — changes grade 1-the seminiferous tubules with discrete germ cells loss, there is an orderly maturation of germ cells from the base to the center of the lumen, but the number of spermatogonia (along the basement membrane), primary and secondary spermatocytes, spermatids, and spermatozoa is slightly reduced. 


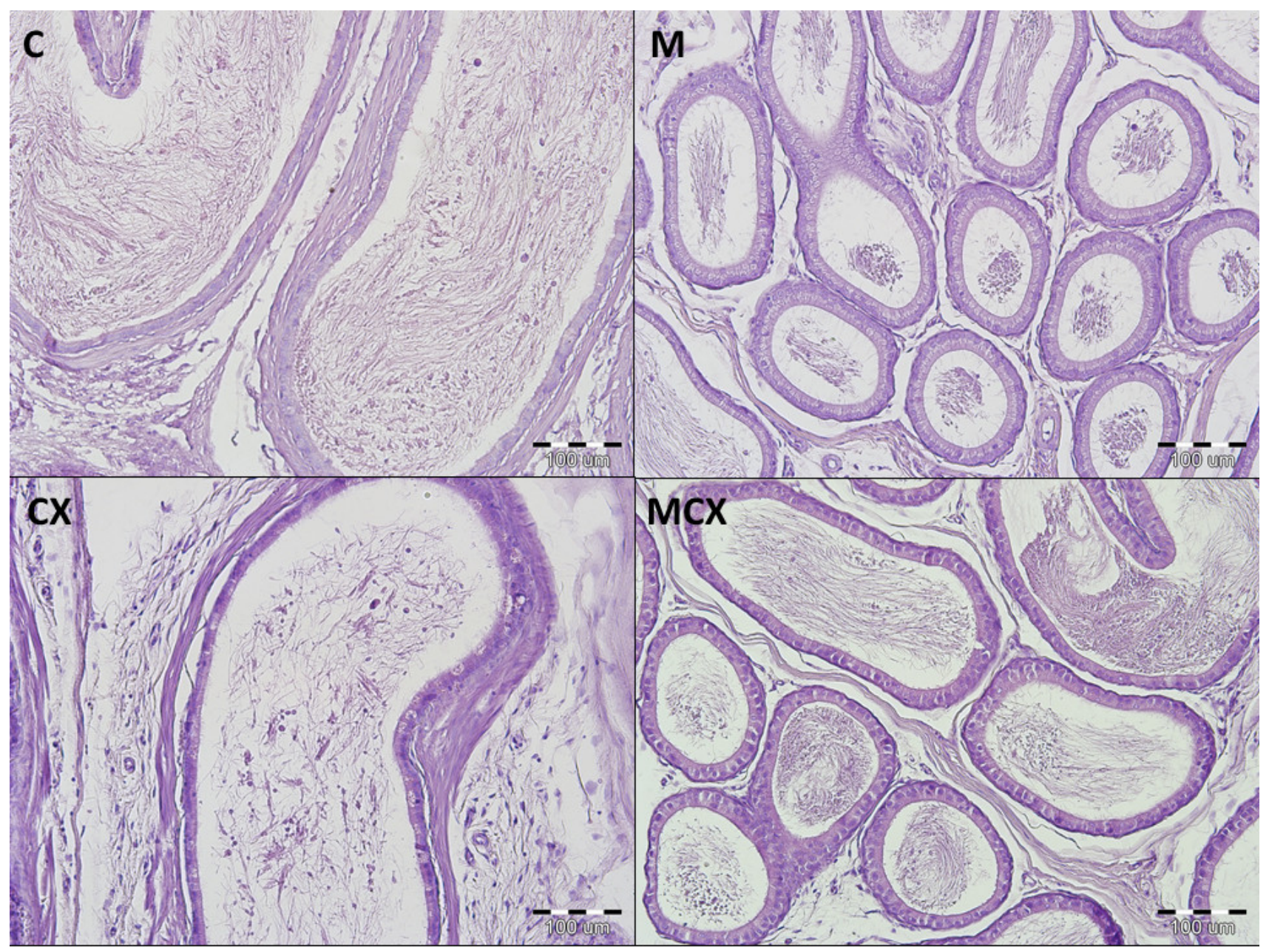

Figure 4. Histological cross-sections of epididymes (HE staining, magnification $200 \times$ ). C—control group-no pathological changes, tubules have thick muscular coat, the lining is composed of tall, ciliated columnar cells, without atypia; M-NaMSA receiving group - no pathological changes, tubules have thick muscular coat, the lining is composed of tall, ciliated columnar cells, without atypia; $\mathrm{CX}$ — cyclophosphamide receiving group—changes grade 1 -tubules have thick muscular coat, the lining is composed of tall, ciliated columnar cells, with some discrete changes; MCX-group receiving cyclophosphamide and NaMSA - no pathological changes, tubules have thick muscular coat, the lining is composed of tall, ciliated columnar cells, without atypia.

\subsection{Urinary Bladder Evaluation}

Hemorrhage, edema, and ulcerations/erosions in the urinary bladders were assessed and pathological changes were also the most significant in the CPX-receiving group. Similarly, treatment for 10 days with NaMSA reversed significantly CPX-induced changes reflected by decreased urinary bladder scoring system shown in Figure 1.

Additionally, in urinary bladders, analysis of bladder score was performed separately for male and female rats and results as shown in Figure 2. In male rats, the most significant pathologies were found in the CPX-receiving group and the addition of NaMSA fully reversed these changes. In female rats, abnormalities caused by CPX were only partly reversed by NaMSA co-administration. Representative histological changes for tested groups for urinary bladders are presented in Figure 5. 


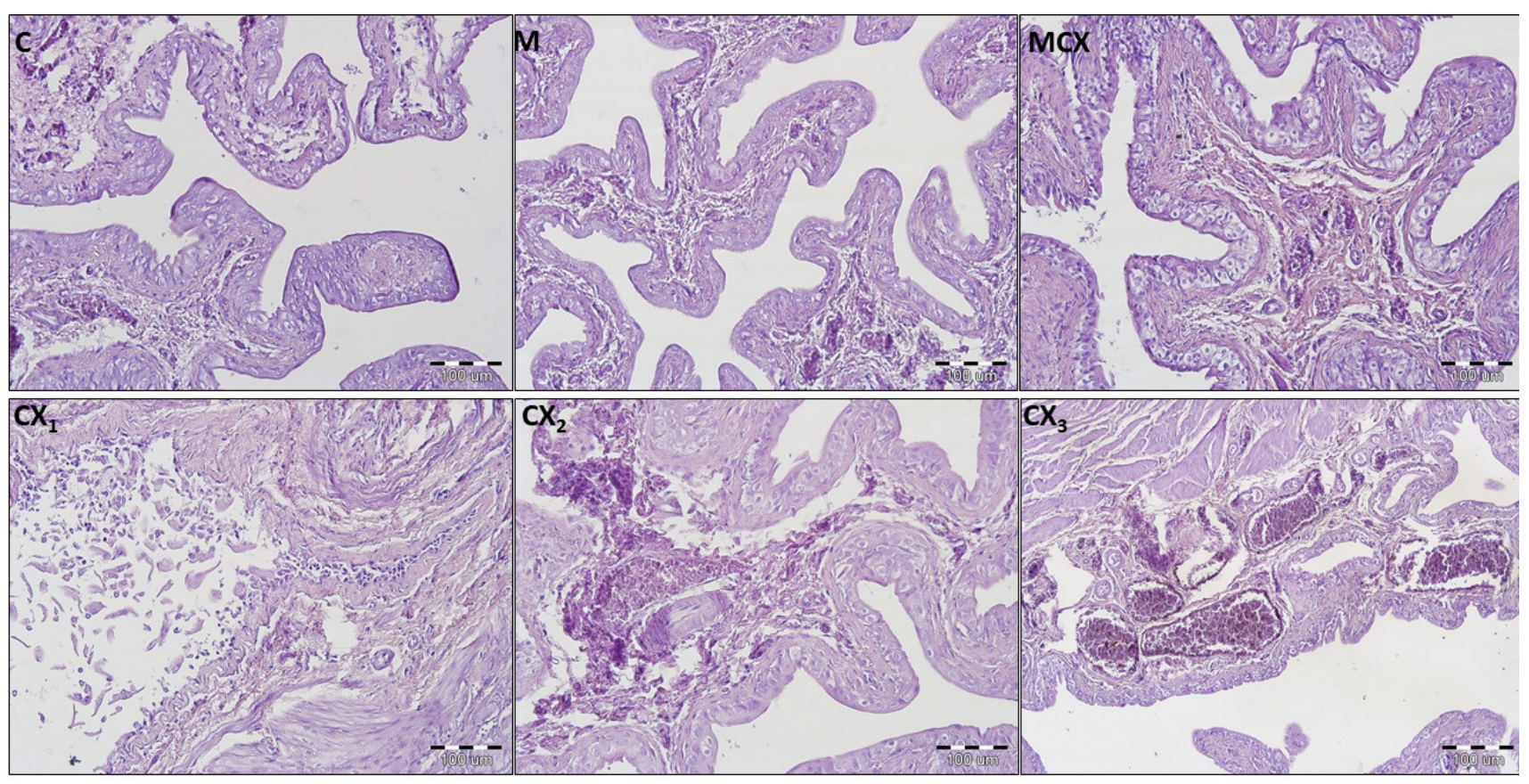

Figure 5. Histological cross-sections of urinary bladders (HE staining, magnification 200 $\times$ ). C—control group—no pathological changes; $\mathrm{M}$ - group receiving NaMSA — edema and discrete hyperemia of submucosa, there are normal 5-7 layers of transitional epithelium without atypia and some slightly dilated blood vessels; MCX-group receiving cyclophosphamide and NaMSA — edema of submucosa, there are normal 5-7 layers of transitional epithelium without atypia and some slightly dilated blood vessels; CX—group receiving cyclophosphamide—selected characteristic abnormalities; CX1-erosion of normal transitional epithelium without inflammation; CX2-edema and discrete hyperemia of submucosa, there are normal 5-7 layers of transitional epithelium without atypia and some slightly dilated blood vessels; CX3-high degree hyperemia of submucosa, there are normal 5-7 layers of transitional epithelium without atypia and some significantly dilated blood vessels.

\section{Discussion}

Cyclophosphamide belongs to the conventional anticancer agents but still is used as an important treatment option for many solid tumors or hematological malignancies, e.g., breast cancer or Hodgkin lymphoma. The drug is also a part of conditioning for a bone marrow transplantation or an alternative immunosuppressant in drug-resistant nephrotic syndrome in children or in systemic lupus erythematosus. Besides myelotoxicity typical for many anticancer drugs, cyclophosphamide causes significant adverse effects in the urinary tract and affects the male reproductive system with oligo- and azoospermia, testicular atrophy and sometimes irreversible infertility [7]. Hemorrhagic cystitis is a potentially life-threatening complication [16] and the recommended prevention with mesna administration with forced saline diuresis is still one of the most often chosen options, but not sufficient in all patients [17]. Therefore, there is a great need to search for new substances to increase efficacy of prevention of CPX-induced toxicities. Natural compounds, especially flavonoids, or their chemically modified derivatives are in the interest of many researches due to their potential anti-inflammatory and antioxidant activities. Morin-5'- sulfonic acid sodium salt (NaMSA) is a water-soluble derivative of naturallyoccurred morin. Morin was found in many fruits and vegetables, e.g., Psidium guajava, Acridocarpus orientalis, Moringa oleifera, Satureja hortensis, all parts of almonds or in seaweed. Natural morin and NaMSA was found to scavenge free radicals and protect from damage caused by oxygen free radicals [18-21]. Among others, generation of free radicals is one of the postulated CPX-induced toxicity in various tissues [22]. We have previously found that NaMSA reversed CPX-induced decrease in superoxide dismutase activity and GSH level in rat kidneys [11] and protected from CPX-caused abnormalities in the gastrointestinal tract, revealed in a histological examination [12]. In this paper, we describe morphological 
changes in rat testes, epididymes, and urinary bladder after administration of CPX in a daily dose of $15 \mathrm{mg} / \mathrm{kg}$ for 10 days. CPX-induced changes in urogenital tract in animals are well described in various experimental models of CPX toxicity. The model of single intraperitoneal injection of CPX in a dose of $200 \mathrm{mg} / \mathrm{kg}$ is often used with the studied compound administered before or after the $\mathrm{CPX}$ injection to induce acute hemorrhagic cystitis or testicular toxicity $[10,23,24]$, but other regimens of CPX administration are also applied, e.g., daily intraperitoneal injection of $100 \mathrm{mg} / \mathrm{kg}$ CPX dose for 3 days [25]. We chose 10 days intragastric administration of CPX in a low daily dose of $15 \mathrm{mg} / \mathrm{kg}$ with concomitant administration of NaMSA $(100 \mathrm{mg} / \mathrm{kg})$ as the potentially protective agent. This resembles more immunosuppressive rather than anticancer scheme, however, in our model we also found significant abnormalities in histological examination in testes, epididymes, and urinary bladders. In testes and epididymes, irregular and diminished seminiferous tubules were described as focal or diffuse. In urinary bladders edema, hemorrhage and urothelial erosions with desquamation of urothelium were found. Changes in the urinary bladders were less pronounced than described by other scientists in acute models of hemorrhagic cystitis induced by intraperitoneal injections of high-dose CPX. In this kind of CPX-induced bladder toxicity urothelial necrosis, vesical edema, increased urothelium thickness, erosion, ulceration, severe hemorrhage, inflammation, leukocyte infiltration, or even fibrosis were noticed $[10,25,26]$.

Flavonoids were, and still are, an emerging topic for scientists due to many potential actions as free radicals scavenging, antitumor, or anti-inflammatory effects. Among various flavonoids, morin is of interest because it may heal injured cells [18]. Some environmental toxins such as titanium dioxide nanoparticles or mercuric chloride $(\mathrm{HgCl} 2)$ upregulate expression of Bax and caspase-3 genes expression and downregulate Bcl-2. Morin or NaMSA may attenuate those changes which, next to the antioxidant activity of both substances, may protect from membrane damage resulting in decreased cell death and apoptosis [18,27].

Little is known about the protective effects of morin or its water-soluble derivativemorin-5'-sulfonic acid sodium salt—on damages caused by cyclophosphamide. Testicular toxicity is also an adverse effect of some other anticancer agents, e.g., procarbazine. Olaynka et al. [28] found that morin significantly restored the procarbazine-induced abnormal sperm parameters (count, motility, percentage of normal sperm). Some studies claim that morin protects testicular tissue from morphological injuries and pathology of sperm count and viability induced by titanium dioxide nanoparticles [27,29]. Pretreatment with morin significantly decreases expression of proinflammatory cytokines such as IL-1, TNF-alpha, NF-kappaB, and histological damage in rat kidney in doxorubicin-induced toxicity [30]. In vitro morin protects from apoptosis of renal proximal tubular cells (HK-2 cell line) caused by endoplasmic reticulum stress [31]. Recent studies also suggest that morin may increase anticancer activity of some conventional anticancer agents, e.g., fludarabine, inhibiting low molecular weight protein tyrosine phosphatase (LMW-PTP) [32], and may inhibit proliferation, migration, and invasion of EJ cells of bladder cancer via many different intracellular mechanisms [33].

To our best knowledge, little is known about the action of morin or its derivative such as NaMSA on damages caused by cyclophosphamide or other toxins in urinary bladder. Based on our preliminary findings, it may be suggested that NaMSA exerts some protective effects in the urinary bladder in rats receiving CPX in low daily doses. The exact mechanism of this activity requires further, detailed studies, also in the well-established acute model of CPX bladder toxicity. The NaMSA effect in urinary bladders seems to be more pronounced in male than female rats, but it also must be confirmed in the future. A study of Bon et al. [34] examined differences in CPX-induced bladder inflammation in male and female rats after administration of a single $100 \mathrm{mg} / \mathrm{kg}$ intraperitoneal dose. In general, they did not observe sex differences in bladder inflammation after CPX. Neither the time of day nor estrous cycle gave significantly different effects on the degree of cystitis but bladder inflammation in female rats was the most severe in rats in estrous stage when 
CPX was administered in the morning. Terado et al. [35] administered intraperitoneally $\mathrm{CPX}$ to ovariectomized or castrated rats and described typical histological changes in bladders in a form of submucosal edema, urothelial damage, hemorrhage, and leukocyte infiltration. Observed pathologies were more severe in ovariectomized females than in the CPX-administered sham-operated females, on the other hand, in male rats castration did not influence the severity of pathological changes in urinary bladder when compared to the sham-operated group. Treatment of ovariectomized females with estrogen ameliorated histological changes induced by CPX administration [35]. It was also found that estrogen administration decreases the severity of inflammation in the bladder in mice model of acute or chronic CPX-induced cystitis [36]. Early clinical data from very few series of cases also suggested some additional benefits in patients treated with conjugated estrogen who received CPX treatment, especially in decreasing hematuria. The mechanism of estrogen's action in controlling the CPX-induced hematuria is still unclear, but some data suggest the action on cellular and cytokine immune response during inflammation, enhanced healing of damaged tissue, and/or improved endothelial cell function [37-39]. In our study, the females were not ovariectomized and we did not check the reproductive phase, so to make conclusions about differences in NaMSA action in bladders in male and females detailed studies are necessary. The degree of pathological changes in bladders of males and females, expressed in 0-6-point scoring system, was not significantly different.

\section{Materials and Methods}

\subsection{Animals}

An experiment was performed after the approval of the Local Ethics Committee for Animal Experiments in Wrocław at the Hirszfeld Institute of Immunology and Experimental Therapy of Polish Academy of Sciences and all experiments were performed in accordance with relevant named guidelines and regulations. There were 48 male and female Wistar rats, obtained from the Animal Research Center at Wroclaw Medical University (Wrocław, Poland), with average weight of $203.5 \mathrm{~g} \pm 17.6 \mathrm{~g}$, housed in standard laboratory conditions ( $12 \mathrm{~h}: 12 \mathrm{~h}$ light-dark cycle, $21-23^{\circ} \mathrm{C}$, free access to standard rat chow and water) arranged in four experimental groups of 12 animals each ( 6 males and 6 females).

\subsection{Design of the Experiment}

The groups were as follows: $\mathrm{C}, \mathrm{M}, \mathrm{CX}$, and MCX, receiving $0.9 \%$ saline solution only (Polpharma S.A., Starogard Gdański, Poland), NaMSA alone (100 mg/kg/day), cyclophosphamide alone (15 mg/kg/day, Sigma, Steinheim, Germany), and CPX (15 mg/kg/day) with NaMSA (100 mg/kg/day), respectively. CPX and NaMSA were administered intragastrically by the tube, after reconstitution in normal saline in $4 \mathrm{~mL} / \mathrm{kg}$ volume for 10 days. Normal saline in group $C$ was given in the equivalent volume. CPX was given at 9 a.m., whereas NaMSA was administered at 2 p.m. as it was described in earlier publications to minimize chemical interaction in the gastrointestinal tract $[11,40,41]$. Morin-5'-sulfonic acid sodium salt was synthesized at the Department of Inorganic and Analytical Chemistry, Rzeszow University of Technology, Poland, according to the methods described previously [42-44]. On the 11th day of the study rats were euthanized by dislocation of cervical vertebrae in deep peritoneal barbiturate anesthesia.

\subsection{Histological Assessment}

Testes and epididymes from male and urinary bladders from male and female rats were isolated, $4 \%$ buffered formalin fixed, paraffin-embedded and cut with a microtome into $5 \mu \mathrm{m}$ thick slices and stained with hematoxylin-eosin for histological examination performed by two independent practiced two pathomorphologists. In testes and epididymes changes in spermatogenic epithelium and in seminiferous tubules epithelium were described as irregular and diminished seminiferous tubules with minimal, low grade $(<25 \%)$ focal changes ( 1 point) or with moderate, high grade ( $\geq 25 \%$ ) diffuse changes ( 2 points). Decreased amount of sperm within the lumen of seminiferous tubules was assessed ac- 
cording to the control group and described as minimal (1 point) or moderate ( 2 points). Every specimen was described by points $(0-6), 0$ points were given when no pathological changes were found in testes, epididymes and sperm count. Microscopic evaluation of urinary bladders assessed hemorrhage, edema, and urothelium loss. Each pathology was scored separately from 0 to 2 points. Scoring system of hemorrhage was as follows: 0 point-none, 1 point - mild, 2 points—severe and edema was scored as: 0 point—none, 1 point-flattening with submucosal edema, 2 points—severe. Erosions in urothelium were scored: 0 points—none, 1 point-minimal lesions, single cells loss, exfoliation of superficial epithelial cells, 2 points-significant mucosal erosion.

\subsection{Statistical Analysis}

Means \pm standard deviation (SD) were used to describe experimental data. Statistical analysis of the effects of the drug on the studied parameters was performed using analysis of variance (ANOVA). After checking the equality of variances by Brown-Forsythe test, specific comparisons between studies groups were done with post-hoc NIR test. Hypotheses were considered positively verified if $p<0.05$. Statistical analysis was performed using STATISTICA 13 PL (StatSoft, Kraków, Poland).

\section{Conclusions}

In conclusion, our preliminary findings suggest that NaMSA may prevent from morphological changes induced by CPX administration in the male reproductive system and in bladders of both sexes, especially in male rats, but this requires further research in other experimental models of CPX administration focused on detailed, potential mechanisms of such action.

Author Contributions: Conceptualization, A.M.-L.; methodology, A.M.-L.; formal analysis, A.M.-L.; investigation, A.M.-L., A.H., D.S. and M.T.; resources, A.S.; writing—original draft preparation, A.M.-L., M.T. and M.S.-B.; writing — review and editing, A.M.-L.; D.K., A.M., B.N., T.S. and A.S.; supervision, A.S.; project administration, A.M.-L.; funding acquisition, A.S.; synthesis of the original compound NaMSA, A.K. All authors have read and agreed to the published version of the manuscript.

Funding: This research received no external funding.

Institutional Review Board Statement: Animal experiment was performed after the approval of the Local Ethics Committee for Animal Experiments in Wrocław at Hirszfeld Institute of Immunology and Experimental Therapy of Polish Academy of Sciences (approval code 36/08) and all experiments were performed in accordance with relevant named guidelines and regulations.

Informed Consent Statement: Not applicable.

Data Availability Statement: The data underlying this article will be shared on request to the corresponding author.

Conflicts of Interest: The authors declare no conflict of interest.

\section{References}

1. Allen, C.M.; Lopes, F.; Mitchell, R.T.; Spears, N. How does chemotherapy treatment damage the prepubertal testis? Reproduction 2018, 156, R209-R233. [CrossRef]

2. Zhu, B.; Zheng, Y.F.; Zhang, Y.Y.; Cao, Y.S.; Zhang, L.; Li, X.G.; Liu, T.; Jiao, Z.Z.; Wang, Q.; Zhao, Z.G. Protective effect of L-carnitine in cyclophosphamide-induced germ cell apoptosis. J. Zhejiang Univ. Sci. B 2015, 16, 780-787. [CrossRef] [PubMed]

3. Ghaleno, L.R.; Alizadeh, A.; Drevet, J.R.; Shahverdi, A.; Valojerdi, M.R. Oxidation of sperm dna and male infertility. Antioxidants 2021, 10, 97. [CrossRef] [PubMed]

4. Yilmaz, N.; Emmungil, H.; Gucenmez, S.; Ozen, G.; Yildiz, F.; Balkarli, A.; Kimyon, G.; Coskun, B.N.; Dogan, I.; Pamuk, O.N.; et al. Incidence of cyclophosphamide-induced urotoxicity and protective effect of mesna in rheumatic diseases. J. Rheumatol. 2015, 42, 1661-1666. [CrossRef]

5. Demlova, R.; Valík, D.; Obermannova, R.; Zdražilová-Dubská, L. The safety of therapeutic monoclonal antibodies: Implications for cancer therapy including immuno-checkpoint inhibitors. Physiol. Res. 2016, 65, S455-S462. [CrossRef] [PubMed]

6. Matz, E.L.; Hsieh, M.H. Review of Advances in Uroprotective Agents for Cyclophosphamide- and Ifosfamide-induced Hemorrhagic Cystitis. Urology 2017, 100, 16-19. [CrossRef] 
7. Cyclophosphamide Cadiasun-Summary of Product Characteristics. 2021. Available online: https://mri.cts-mrp.eu/hu (accessed on 31 January 2021).

8. Arena, A.C.; Jorge, B.C.; Silva, M.C.; de Barros, A.L.; Fernandes, A.A.H.; Nóbrega, R.H.; Martinez, E.R.M.; Cardoso, C.A.L.; Anselmo-Franci, J.A.; Muzzi, R.M. Acrocomia aculeata oil: Beneficial effects on cyclophosphamide-induced reproductive toxicity in male rats. Andrologia 2018, 50, 1-11. [CrossRef]

9. Potnuri, A.G.; Allakonda, L.; Lahkar, M. Crocin attenuates cyclophosphamide induced testicular toxicity by preserving glutathione redox system. Biomed. Pharmacother. 2018, 101, 174-180. [CrossRef]

10. Wu, K.C.; Lin, W.Y.; Sung, Y.T.; Wu, W.Y.; Cheng, Y.H.; Chen, T.S.; Chiang, B.J.; Chien, C.T. Glycine tomentella hayata extract and its ingredient daidzin ameliorate cyclophosphamide-induced hemorrhagic cystitis and oxidative stress through the action of antioxidation, anti-fibrosis, and anti-inflammation. Chin. J. Physiol. 2019, 62, 188-195. [CrossRef]

11. Merwid-Lą, A.; Trocha, M.; Chlebda, E.; Sozański, T.; Magdalan, J.; Ksiądzyna, D.; Kopacz, M.; Kuźniar, A.; Nowak, D.; Pieśniewska, M.; et al. Effects of morin-5'-sulfonic acid sodium salt (NaMSA) on cyclophosphamide-induced changes in oxido-redox state in rat liver and kidney. Hum. Exp. Toxicol. 2012, 31, 812-819. [CrossRef]

12. Merwid-Ląd, A.; Ksiądzyna, D.; Hałoń, A.; Chlebda-Sieragowska, E.; Trocha, M.; Szandruk, M.; Sozański, T.; Magdalan, J.; Kopacz, M.; Kuźniar, A.; et al. Impact of morin-5'-sulfonic acid sodium salt on cyclophosphamide-induced gastrointestinal toxicity in rats. Pharmacol. Rep. 2015, 67, 1259-1263. [CrossRef]

13. Salimnejad, R.; Soleimani Rad, J.; Mohammad Nejad, D.; Roshangar, L. Effect of ghrelin on total antioxidant capacity, lipid peroxidation, sperm parameters and fertility in mice against oxidative damage caused by cyclophosphamide. Andrologia 2018, 50, 1-7. [CrossRef]

14. Onaolapo, A.Y.; Oladipo, B.P.; Onaolapo, O.J. Cyclophosphamide-induced male subfertility in mice: An assessment of the potential benefits of Maca supplement. Andrologia 2018, 50, e12911. [CrossRef]

15. Zhang, X.; Gao, S.; Tanaka, M.; Zhang, Z.; Huang, Y.; Mitsui, T.; Kamiyama, M.; Koizumi, S.; Fan, J.; Takeda, M.; et al. Carbenoxolone inhibits TRPV4 channel-initiated oxidative urothelial injury and ameliorates cyclophosphamide-induced bladder dysfunction. J. Cell. Mol. Med. 2017, 21, 1791-1802. [CrossRef]

16. Kaplan, J.R.; Wolf, J.S. Efficacy and Survival Associated With Cystoscopy and Clot Evacuation for Radiation or Cyclophosphamide Induced Hemorrhagic Cystitis. J. Urol. 2009, 181, 641-646. [CrossRef]

17. Moy, B.; Linder, B.J.; Chao, N.J.; Gounder, M.M. Hemorrhagic cystitis in cancer patients. UpToDate 2018, 11, 1-29.

18. Venkatesan, R.S.; Sadiq, A.M.M. Effect of morin-5'-sulfonic acid sodium salt on the expression of apoptosis related proteins caspase 3, Bax and Bcl 2 due to the mercury induced oxidative stress in albino rats. Biomed. Pharmacother. 2017, 85, 202-208. [CrossRef]

19. Emre, İ.; Kurşat, M.; Yilmaz, Ö.; Erecevit, P. Chemical compositions, radical scavenging capacities and antimicrobial activities in seeds of Satureja hortensis L. and Mentha spicata L. subsp. spicata from Turkey. Braz. J. Biol. 2020, 81, 144-153. [CrossRef]

20. Caicedo-Lopez, L.H.; Cuellar-Nuñez, M.L.; Luzardo-Ocampo, I.; Campos-Vega, R.; Lóarca-Piña, G. Colonic metabolites from digested Moringa oleifera leaves induced HT-29 cell death via apoptosis, necrosis, and autophagy. Int. J. Food Sci. Nutr. 2020, 1-14. [CrossRef]

21. Caselli, A.; Cirri, P.; Santi, A.; Paoli, P. Morin: A Promising Natural Drug. Curr. Med. Chem. 2016, 23, 774-791. [CrossRef] [PubMed]

22. Abraham, P.; Isaac, B.; Ramamoorthy, H.; Natarajan, K. Oral Glutamine Attenuates Cyclophosphamide-Induced Oxidative Stress in the Bladder but Does Not Prevent Hemorrhagic Cystitis in Rats. J. Med. Toxicol. 2011, 7, 118-124. [CrossRef]

23. Kaya, C.; Baseskioglu, A.B.; Yigitaslan, S.; Ozatik, F.Y.; Ozatik, O.; Uslu, S. The therapeutic potential of amifostine on cyclophosphamide-induced testicular dysfunction in rats: An experimental study. Int. J. Reprod. Biomed. 2019, 17, $245-252$. [CrossRef]

24. Caglayan, C. The effects of naringin on different cyclophosphamide-induced organ toxicities in rats: Investigation of changes in some metabolic enzyme activities. Environ. Sci. Pollut. Res. 2019, 26, 26664-26673. [CrossRef] [PubMed]

25. Sucic, M.; Luetic, K.; Jandric, I.; Drmic, D.; Sever, A.Z.; Vuletic, L.B.; Halle, Z.B.; Strinic, D.; Kokot, A.; Seiwerth, R.S.; et al. Therapy of the rat hemorrhagic cystitis induced by cyclophosphamide. Stable gastric pentadecapeptide BPC 157, L-arginine, L-NAME. Eur. J. Pharmacol. 2019, 861. [CrossRef] [PubMed]

26. Wróbel, A.; Serefko, A.; Bańczerowska-Górska, M.; Szopa, A.; Dudka, J.; Poleszak, E. Intravesical administration of blebbistatin prevents cyclophosphamide-induced toxicity of the urinary bladder in female Wistar rats. Neurourol. Urodyn. 2019, 1044-1052. [CrossRef] [PubMed]

27. Shahin, N.N.; Mohamed, M.M. Nano-sized titanium dioxide toxicity in rat prostate and testis: Possible ameliorative effect of morin. Toxicol. Appl. Pharmacol. 2017, 334, 129-141. [CrossRef]

28. Olayinka, E.T.; Ore, A.; Adeyemo, O.A.; Ola, O.S. The role of flavonoid antioxidant, morin in improving procarbazine-induced oxidative stress on testicular function in rat. Porto Biomed. J. 2019, 4, e28. [CrossRef] [PubMed]

29. Hussein, M.M.A.; Gad, E.; Ahmed, M.M.; Arisha, A.H.; Mahdy, H.F.; Swelum, A.A.A.; Tukur, H.A.; Saadeldin, I.M. Amelioration of titanium dioxide nanoparticle reprotoxicity by the antioxidants morin and rutin. Environ. Sci. Pollut. Res. 2019, 26, 29074-29084. [CrossRef] [PubMed]

30. Kuzu, M.; Yıldırım, S.; Kandemir, F.M.; Küçükler, S.; Çağlayan, C.; Türk, E.; Dörtbudak, M.B. Protective effect of morin on doxorubicin-induced hepatorenal toxicity in rats. Chem. Biol. Interact. 2019, 308, 89-100. [CrossRef] 
31. Mo, J.S.; Choi, D.; Han, Y.R.; Kim, N.; Jeong, H.S. Morin has protective potential against ER stress induced apoptosis in renal proximal tubular HK-2 cells. Biomed. Pharmacother. 2019, 112. [CrossRef]

32. Capitani, N.; Lori, G.; Paoli, P.; Patrussi, L.; Troilo, A.; Baldari, C.T.; Raugei, G.; D'Elios, M.M. LMW-PTP targeting potentiates the effects of drugs used in chronic lymphocytic leukemia therapy. Cancer Cell Int. 2019, 19, 1-9. [CrossRef]

33. Shin, S.S.; Won, S.Y.; Noh, D.H.; Hwang, B.; Kim, W.J.; Moon, S.K. Morin Inhibits Proliferation, Migration, and Invasion of Bladder Cancer EJ Cells via Modulation of Signaling Pathways, Cell Cycle Regulators, and Transcription Factor-Mediated MMP-9 Expression. Drug Dev. Res. 2017, 78, 81-90. [CrossRef]

34. Bon, K.; Lantéri-Minet, M.; Menétrey, D.; Berkley, K.J. Sex, time-of-day and estrous variations in behavioral and bladder histological consequences of cyclophosphamide-induced cystitis in rats. Pain 1997, 73, 423-429. [CrossRef]

35. Terado, M.; Nomura, M.; Mineta, K.; Nishii, H.; Fujimoto, N.; Sasaguri, T.; Sasaguri, Y.; Matsumoto, T. Involvement of estrogen in the pathogenesis of cyclophosphamide-induced cystitis in rats. Endocrine 2005, 26, 55-63. [CrossRef]

36. Martinez-Ferrer, M.; Iturregui, J.M.; Uwamariya, C.; Starkman, J.; Sharif-Afshar, A.R.; Suzuki, K.; Visedsindh, W.; Matusik, R.J.; Dmochowski, R.R.; Bhowmick, N.A. Role of nicotinic and estrogen signaling during experimental acute and chronic bladder inflammation. Am. J. Pathol. 2008, 172, 59-67. [CrossRef]

37. Liu, Y.K.; Harty, J.I.; Steinbock, G.S.; Holt, H.A.; Goldstein, D.H.; Amin, M. Treatment of radiation or cyclophosphamide induced hemorrhagic cystitis using conjugated estrogen. J. Urol. 1990, 144, 41-43. [CrossRef]

38. Ordemann, R.; Naumann, R.; Geissler, G.; Bornhauser, M.; Schuler, U.; Ehninger, G. Encouraging results in the treatment of haemorrhagic cystitis with estrogen-report of 10 cases and review of the literature. Bone Marrow Transplant. 2000, 25, 981-985. [CrossRef]

39. Kopterides, P.; Theodorakopoulou, M.; Mentzelopoulos, S.; Armaganidis, A. Cyclophosphamide-induced hemorrhagic cystitis successfully treated with conjugated estrogens. Am. J. Hematol. 2005, 80, 166-167. [CrossRef]

40. Magdalan, J.; Szelag, A.; Kopacz, M.; Kuźniar, A.; Nowak, D.; Kowalski, P.; Pieśniewska, M. Morin-5'-Sulfonic Acid Sodium Salt as an Antidote in the Treatment of Acute Chromium Poisoning in Rats. Adv. Clin. Exp. Med. 2006, 15, 767-776.

41. Magdalan, J.; Szelag, A.; Kopacz, M.; Kuźniar, A.; Nowak, D.; Kowalski, P.; Pieśniewska, M. Quercetin-5'-Sulfonic Acid Sodium Salt and Morin-5'-Sulfonic Acid Sodium Salt as Antidotes in the Treatment of Acute Inorganic Mercury PoisoningExperimental Studies. Adv. Clin. Exp. Med. 2006, 15, 581-587.

42. Kopacz, M. Sulfonic derivatives of morin. Pol. J. Chem. 1981, 55, 225-229.

43. Kopacz, M. Quercetin- and Morinsulfonates as Analytical Reagents. J. Anal. Chem. 2003, 58, 225-229. [CrossRef]

44. Kuźniar, A.; Kopacz, M.; Nowak, D. Characterization and spectroscopic study of new complexes of Cd(II), $\mathrm{Hg}$ (II) and Pb(II) with the sodium salt of morin-5'-sulfonic acid. J. Coord. Chem. 2008, 61, 1005-1018. [CrossRef] 